\title{
Analysis of gene expression from the Wolbachia genome of a filarial nematode supports both metabolic and defensive roles within the symbiosis
}

\author{
Alistair C. Darby, ${ }^{1}$ Stuart D. Armstrong, ${ }^{2}$ Germanus S. Bah, ${ }^{2,3}$ Gaganjot Kaur, ${ }^{4}$ \\ Margaret A. Hughes, ${ }^{1}$ Suzanne M. Kay, ${ }^{1}$ Pia Koldkjær, ${ }^{1}$ Lucille Rainbow, ${ }^{1}$ \\ Alan D. Radford, ${ }^{2}$ Mark L. Blaxter, ${ }^{4}$ Vincent N. Tanya, ${ }^{3}$ Alexander J. Trees, ${ }^{2}$ \\ Richard Cordaux, ${ }^{5}$ Jonathan M. Wastling, ${ }^{2}$ and Benjamin L. Makepeace ${ }^{2,6}$ \\ ${ }^{1}$ Institute of Integrative Biology and the Centre for Genomic Research, Biosciences Building, University of Liverpool, Liverpool, \\ Merseyside L69 7ZB, United Kingdom; ${ }^{2}$ Institute of Infection \& Global Health, Liverpool Science Park IC2, University of Liverpool, \\ Liverpool, Merseyside L3 5RF, United Kingdom; ${ }^{3}$ Institut de Recherche Agricole pour le Développement, Regional Centre of Wakwa, \\ Ngaoundéré, BP65 Adamawa Region, Cameroon; ${ }^{4}$ Institute of Evolutionary Biology and the GenePool Genomics Facility, School \\ of Biological Sciences, University of Edinburgh, Edinburgh EH9 3JT, United Kingdom; ${ }^{5}$ Laboratoire Ecologie et Biologie des Interactions \\ (UMR CNRS 7267), Equipe Ecologie Evolution Symbiose, Université de Poitiers, 86022 Poitiers CEDEX, France
}

\begin{abstract}
The $\alpha$-proteobacterium Wolbachia is probably the most prevalent, vertically transmitted symbiont on Earth. In contrast with its wide distribution in arthropods, Wolbachia is restricted to one family of animal-parasitic nematodes, the Onchocercidae. This includes filarial pathogens such as Onchocerca volvulus, the cause of human onchocerciasis, or river blindness. The symbiosis between filariae and Wolbachia is obligate, although the basis of this dependency is not fully understood. Previous studies suggested that Wolbachia may provision metabolites (e.g., haem, riboflavin, and nucleotides) and/or contribute to immune defense. Importantly, Wolbachia is restricted to somatic tissues in adult male worms, whereas females also harbor bacteria in the germline. We sought to characterize the nature of the symbiosis between Wolbachia and 0 . ochengi, a bovine parasite representing the closest relative of $O$. volvulus. First, we sequenced the complete genome of Wolbachia strain wOo, which revealed an inability to synthesize riboflavin de novo. Using RNA-seq, we also generated endobacterial transcriptomes from male soma and female germline. In the soma, transcripts for membrane transport and respiration were up-regulated, while the gonad exhibited enrichment for DNA replication and translation. The most abundant Wolbachia proteins, as determined by geLC-MS, included ligands for mammalian Toll-like receptors. Enzymes involved in nucleotide synthesis were dominant among metabolism-related proteins, whereas the haem biosynthetic pathway was poorly represented. We conclude that Wolbachia may have a mitochondrion-like function in the soma, generating ATP for its host. Moreover, the abundance of immunogenic proteins in wOo suggests a role in diverting the immune system toward an ineffective antibacterial response.
\end{abstract}

[Supplemental material is available for this article.]

The $\alpha$-proteobacterium Wolbachia is estimated to infect two-thirds of all arthropod species (Hilgenboecker et al. 2008) and thus is probably the most abundant vertically transmitted organism in the biosphere. However, it also has a much more restricted prevalence in two families of nematode worms: about 20 species of animal-parasitic Onchocercidae (superfamily Filarioidea; the filariae) (Ferri et al. 2011) and at least two species of plant-parasitic Pratylenchidae (Haegeman et al. 2009). The most salient characteristic of Wolbachia is its astonishing ability to induce a wide diversity of phenotypes in arthropod hosts, from reproductive manipulations, such as cytoplasmic incompatibility and male-killing, to mutualistic roles, including pathogen protection and enhanced fecundity. Until recently, obligate dependencies on Wolbachia had not been recognized in arthropods, but a small number of species in dispa-

\footnotetext{
${ }^{6}$ Corresponding author

E-mail blm1@liv.ac.uk

Article published online before print. Article, supplemental material, and publication date are at http://www.genome.org/cgi/doi/10.1101/gr.138420.112. Freely available online through the Genome Research Open Access option.
}

rate taxa require these symbionts for normal reproduction or development (Dedeine et al. 2001; Timmermans and Ellers 2009; Hosokawa et al. 2010; Miller et al. 2010). In contrast, obligate mutualism is widespread in the Onchocercidae, where antibiotic treatment induces retarded larval growth (Hoerauf et al. 1999), embryostasis in females (Bandi et al. 1999), and even death of adult filariae (Langworthy et al. 2000). Thus, this symbiotic relationship has been exploited as a drug target in the search for practicable adulticidal chemotherapy against human filarial pathogens, such as Onchocerca volvulus (the etiological agent of onchocerciasis, or river blindness) and Brugia malayi (one species responsible for lymphatic filariasis [LF]) (Hoerauf 2008). In adults of B. malayi, $O$. volvulus, and Onchocerca ochengi (a parasite of cattle representing the closest relative of $O$. volvulus) (Trees 1992; Morales-Hojas et al. 2006), Wolbachia are found both in the somatic hypodermal cords that run along the length of the worms and in the germinal zones of the female gonad, where they are transmitted into the oocytes and maintained throughout larval development. However, they are completely absent from the reproductive system of adult males (Landmann et al. 2010). 
Wolbachia are divided into about 10 supergroups on the basis of phylogenetic distance (Lo et al. 2007). Most symbionts in filarial nematodes are found in supergroups C, D (which both lack members in arthropods), or $\mathrm{F}$ (which also contains strains from bedbugs and termites, among other arthropods). To date, four Wolbachia genomes have been completed: two from group A ( $w \mathrm{Mel}, 1.3 \mathrm{Mb}$ [Wu et al. 2004], and $w \mathrm{Ri}, 1.5 \mathrm{Mb}$ [Klasson et al. 2009] from Drosophila melanogaster and Drosophila simulans, respectively), one from group B ( $w$ Pip, $1.5 \mathrm{Mb}$ [Klasson et al. 2008] from the mosquito Culex pipiens), and one from group D ( $w \mathrm{Bm}$, $1.1 \mathrm{Mb}$ [Foster et al. 2005] from B. malayi). Comparative analysis of the $w \mathrm{Bm}$ genome and that of B. malayi suggested that Wolbachia provisions the worm with haem, riboflavin, and flavin adenine dinucleotide (FAD), since the B. malayi nuclear genome does not encode complete pathways for these cofactors (Foster et al. 2005; Ghedin et al. 2007). In addition, and unusually for a member of the Rickettsiales, $w \mathrm{Bm}$ retains the de novo nucleotide synthesis pathway and thus could also supply this resource during periods of high metabolic demand (Foster et al. 2005). Conversely, the almost complete lack of amino acid synthesis pathways in $w \mathrm{Bm}$ clearly defined the nature of the mutualism in the reverse direction. More recently, an alternative or additional role for strain $w \mathrm{Oo}$ (supergroup C) in O. ochengi has been proposed, as this symbiont stimulates an ineffective neutrophilic immune response in the bovine host (as also observed in human onchocerciasis) that apparently prevents the degranulation of eosinophils against adult worms (Hansen et al. 2011). This may represent a form of defensive mutualism.

Here, we present the most comprehensive molecular analysis of a single Wolbachia strain performed to date. First, we sequenced the complete genome of $w \mathrm{Oo}$ and determined that it is the smallest yet described for the taxon. Second, we obtained complete transcriptomes from Wolbachia for the first time and compared the global gene expression between somatic and gonad tissue. Finally, we identified the most abundant protein species in wOo from adult female worms. Our data reveal important dissimilarities between $w \mathrm{Bm}$ and $w$ Oo in terms of metabolic capability, the density of insertion sequences (ISs), and the repertoire of repeat-motif containing proteins. Moreover, our gene expression analyses indicate potential roles for $w O$ Oo in both energy production in the somatic tissue and modulation of the mammalian immune response but fail to provide strong support for the provisioning of vitamins or cofactors by this strain.

\section{Results}

\section{The genome of Wolbachia strain wOo is highly degraded}

At $0.96 \mathrm{Mb}$, the $w$ Oo genome is the most reduced Wolbachia genome sequenced to date ( $11 \%$ smaller than that of $w \mathrm{Bm})$, and it also exhibits the lowest $\mathrm{G}+\mathrm{C}$ content and gene density for any Wolbachia genome (Fig. 1; Supplemental Tables S1, S2). Although $w$ Oo shares several regions of microsynteny with $w \mathrm{Bm}$, gross chromosomal organization is markedly different between these strains, while conservation of gene order is reduced to the scale of only two to five genes between $w O$ Ond the Wolbachia genomes of insects (Supplemental Fig. S1). In addition, wOo exhibits the most extreme GC skew of any Wolbachia genome (Supplemental Fig. S2), which may reflect ancient gene order stability and, consequently, the accumulation of mutations on each DNA strand (Rocha 2004). The features that have been lost during reductive evolution of the $w$ Oo genome include transposable elements. Indeed, we only detected six IS copies (Supplemental Table S3), accounting for $<0.5 \%$ of the genome, and no group II introns. This

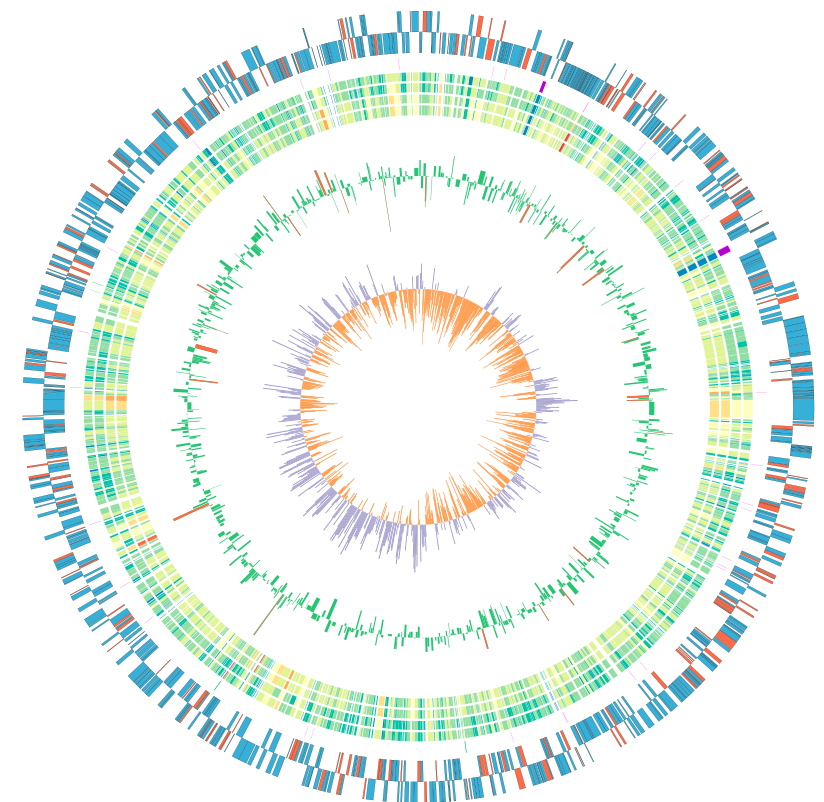

Figure 1. The chromosomal structure of wOo. Circles are numbered sequentially from the perimeter to the center. Circles 1 and 2 represent protein-coding genes on the positive and negative strands, respectively, with intact CDS colored blue and pseudogenes in red; the third circle shows structural RNA genes (rRNA, purple; sRNA, green; and tRNA, pink); circles 4-7 are heat-maps of transcript counts in male soma $(4,5)$ and female gonad $(6,7)$, with high expression colored red and low expression in blue; circle 8 is a plot of differential expression (DE) between male soma (outer profile) and female gonad (inner profile), where red coloration indicates statistically significant $D E$ at $P<0.05$; and circle 9 represents the percentage of $G C$ skew $[(G-C) /(G+C)]$ for each DNA strand. Note that expression from tRNA and rRNA genes was forced to baseline to facilitate visualization of mRNA expression.

is in marked contrast with all other Wolbachia genomes, in which ISs (in $w \mathrm{Bm}$ and insect strains) and group II introns (in insect strains only) are found in high abundance (Supplemental Table S4; Cerveau et al. 2011; Leclercq et al. 2011).

To define the unique set of protein-coding genes that are absent in strain $w$ Oo but present in all of the other completed Wolbachia genomes, we performed an orthologous cluster analysis. Genes that were apparently retained in wOo were then further characterized as intact or pseudogenized. In total, 88 genes have been uniquely lost or pseudogenized in the $w$ Oo genome, of which 29 encode hypothetical proteins (Fig. 2). The remaining genes with a robust or putative annotation are predicted to be involved in DNA replication and repair, membrane transport, potential interactions with eukaryotes (repeat-motif proteins), and enzymes from cofactor synthesis and secondary metabolism pathways. Almost every component of the homologous recombination machinery is absent or pseudogenized in the wOo genome, including all members of the RecFOR repair pathway and the RuvABC complex that resolves Holliday junctions, and proteins conserved in almost all bacteria that could potentially complement these losses (RecA and RecG). The repertoire of membrane transporters is also somewhat depleted in the $w$ Oo genome. However, all subunits of the $\mathrm{F}_{\mathrm{o}} \mathrm{F}_{1}$ ATPase and the $\mathrm{ABC}$ transporters that mediate the uptake of zinc (ZnuABC), ferric iron (AfuABC), and phosphate (PstSCAB) have been retained in $w \mathrm{Oo}$, alongside a $\mathrm{Na}+/ \mathrm{H}+$ anti-porter that is absent in $w \mathrm{Bm}$. Moreover, we determined that the suite of genes associated with peptidoglycan synthesis is identical between $w O$ 


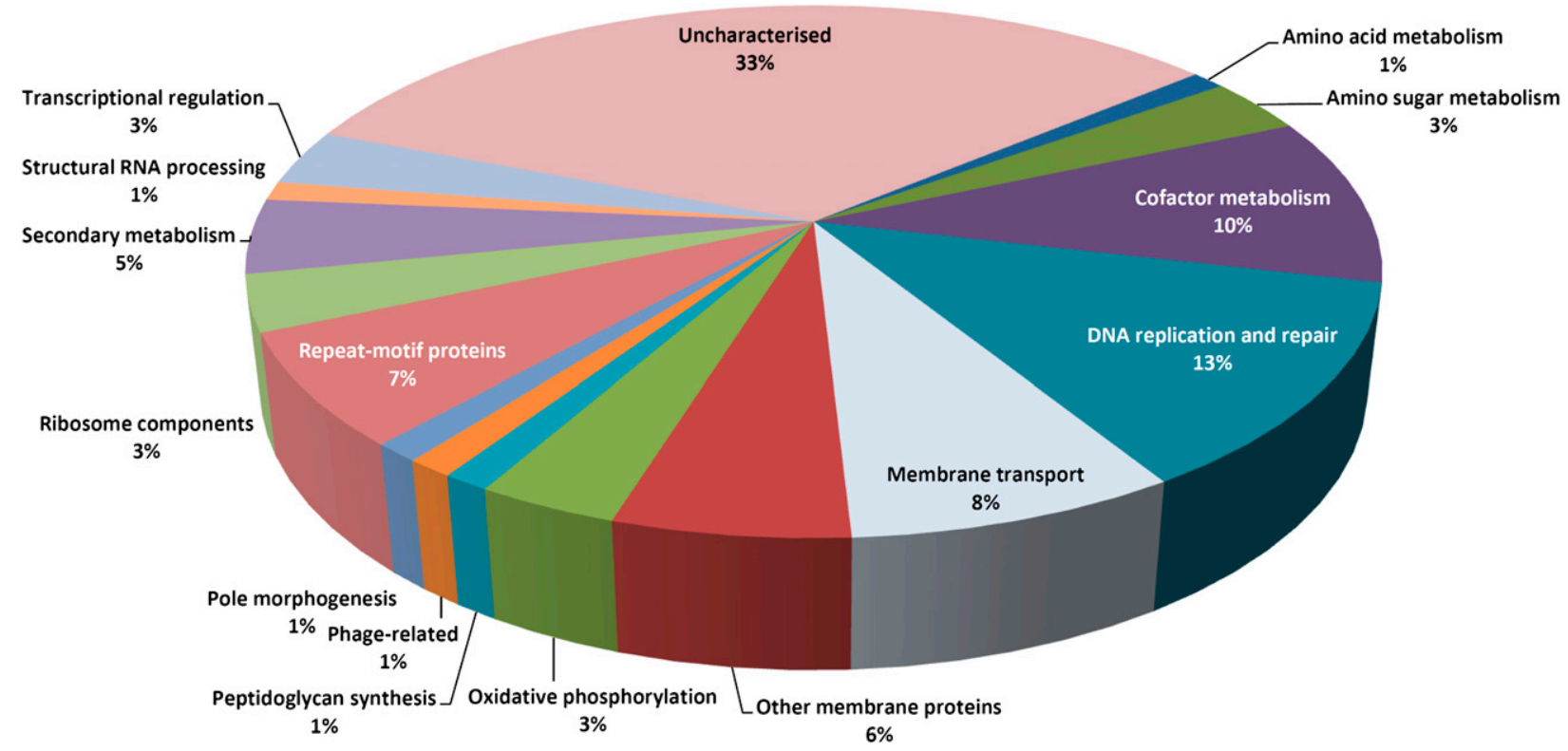

Figure 2. Gene loss from the wOo genome. Orthologous cluster analysis identified 88 genes that are present in $w B m, w M e l, w P i p$, and $w R i$ but that are lost or pseudogenized in wOo. These genes were manually classified into functional categories using the National Center for Biotechnology Information Conserved Domain Database.

and $w \mathrm{Bm}$ (Henrichfreise et al. 2009), with the important exception of the bifunctional N-succinyldiaminopimelate-aminotransferase/ acetylornithine transaminase gene, $\arg D$, which is pseudogenized in wOo (Supplemental Table S5).

As cofactor metabolism is of particular interest in the context of the nutritional provisioning hypothesis, we examined the metabolic capabilities of $w \mathrm{Oo}$ in relation to those of $w \mathrm{Bm}$. Notably, in contrast with $w \mathrm{Bm}$ (Foster et al. 2005), most enzymes in the riboflavin pathway (including the final component, FAD synthase) have been lost or pseudogenized in $w O 0$, with only the first gene in the pathway (ribA) remaining intact. Furthermore, the incomplete pathways for biotin, pantothenate, and coenzyme-A biosynthesis in $w \mathrm{Bm}$ have been almost entirely lost from the $w$ Oo genome, and isoprenoid synthesis (secondary metabolism) (Fig. 2) is also severely restricted. However, all seven components of the haem pathway found in the other Wolbachia genomes are present in $w$ Oo. We note that in addition to the canonical enzymes of this pathway, all of the completed Wolbachia genomes contain a gene for HemY, a membrane-bound protein that can oxidize protoporphyrinogen IX in Bacillus subtilis (Hansson and Hederstedt 1994). Thus, hem $Y$ may complement protoporphyrinogen-IX oxidase (hem $G)$, which is absent in Wolbachia and most other $\alpha$-proteobacteria (Foster et al. 2005). The $w$ Oo genome also contains the six cytochrome $c$ maturation ( $\mathrm{ccm}$ ) genes present in $w \mathrm{Bm}$ and the insect strains, which are responsible for the covalent attachment of haem to apocytochromes; whereas the gene for bacterioferritin (Bfr), a haem-storage protein, has been pseudogenized. We identified, in contrast with the overall pattern of advanced genomic degradation in $w \mathrm{Oo}$, a downstream folate synthesis pathway in this genome, which is also present in $w \mathrm{Ri}$, but not in $w \mathrm{Bm}, w \mathrm{Mel}$, and $w$ Pip. As folate plays a key role in the methylation of DNA, these differences suggest that Wolbachia strains vary in their dependency on scavenging from the host for this essential cofactor.

To determine whether the genomes of $w \mathrm{Oo}$ and $w \mathrm{Bm}$ lack common features that are conserved among all of the complete genomes from insect strains, we defined a repertoire of orthologous clusters that are shared among $w \mathrm{Mel}, w$ Pip, and $w$ Ri only (Supplemental Fig. S3). This analysis confirmed the current paradigm that the major genomic distinctions between insect and filarial strains of Wolbachia can be attributed to prophage-related genes and those encoding repeat-motif proteins (especially ankyrin domains). We also calculated that the core set of orthologs shared between all of the completed Wolbachia genomes, including wOo, totals 575 genes (Supplemental Table S6). A comparison between this core set and those of Holman et al. (2009) (based on computational rankings of the essentiality of genes in the $w \mathrm{Bm}$ genome by two different methods) displayed good concordance, as only three genes with high essentiality scores were absent from a Wolbachia genome (Supplemental Table S7). Notably, all of the genes encoding the type-IV secretion system are also intact in wOo (Supplemental Table S8) and conserved across all other Wolbachia genomes (Pichon et al. 2009).

\section{The Wolbachia transcriptome reveals a constitutive heat-shock response}

To characterize the Wolbachia transcriptome, we performed RNAseq on both whole adult male worms and gonads microdissected from adult female worms. Although only $\sim 5 \%$ of reads mapped to the $w$ Oo genome, almost $98 \%$ of predicted gene models (whether intact or pseudogenized) were classified as "expressed" (i.e., a minimum of 10 cumulative reads were detected across four independent biological samples). However, gene models containing an intact CDS were expressed at a significantly higher level than were pseudogenes $(P<0.001)$ (Supplemental Fig. S4). To determine the distribution of gene function across the transcriptome, we classified protein-coding genes in the $w$ Oo genome using a combination of databases (Fig. 3). This analysis revealed that protein metabolism (including translation) was the most highly expressed functional category, followed by RNA metabolism (including transcription) and stress response. The latter subsystem was dominated by proteins that mediate redox reactions via thiol groups, 


$\square$ Amino Acids and Derivatives
$\square$ Carbohydrates
$\square$ Cell Division and Cell Cycle
$\square$ Cell Wall and Capsule
$\square$ Cofactors, Vitamins, Prosthetic Groups, Pigments
$\square$ DNA Metabolism
$\square$ Fatty Acids, Lipids, and Isoprenoids
$\square$ Membrane Transport
$\square$ Miscellaneous
$\square$ Nitrogen Metabolism
$\square$ Nucleosides and Nucleotides

\author{
$\square$ phages, Prophages, Transposable elements, Plasmids \\ $\square$ Phosphorus Metabolism \\ $\square$ Potassium Metabolism \\ $\square$ Protein Metabolism \\ $\square$ Regulation and Cell signaling \\ Respiration \\ $\square$ RNA Metabolism \\ $\square$ stress Response \\ $\square$ Uncharacterised \\ $\square$ Virulence, Disease and Defense
}

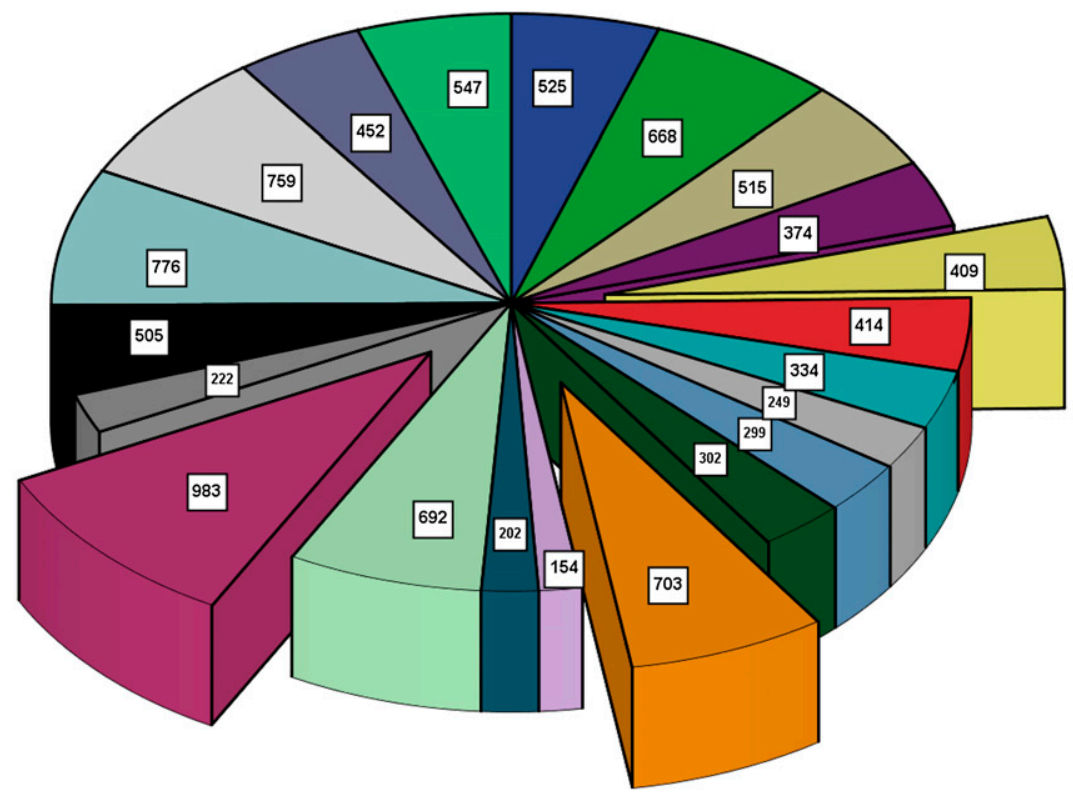

Figure 3. Classification of the wOo transcriptome. The wOo genome was categorized using a combination of subsystems from the SEED database, additional pathway descriptions from the Kyoto Encyclopaedia of Genes and Genomes, and manual curation based on the National Center for Biotechnology Information Conserved Domain Database. The number of transcript reads per functional category is shown in each slice of the pie-chart and represents the mean (i.e., reads are normalized to the total number of genes per subsystem). Exploded slices show (in clockwise order from 12 o'clock) "cofactors, vitamins, prosthetic groups, pigments"; "nucleosides and nucleotides"; and "protein metabolism."

including thioredoxins, peroxiredoxins, glutaredoxins, and glutathione S-transferases. Of the two functional categories that have been proposed to support nutritional provisioning in the symbiosis with filariae, nucleoside and nucleotide metabolism was well represented, whereas pathways for the biosynthesis of cofactors and vitamins were expressed at a relatively low level. Remarkably, of the highly abundant transcripts ranked within the top 20, five (groEL, groES, clpB, dnaK, and lon) are for chaperones or proteases associated with the heat-shock response (Supplemental Table S6), indicating constitutive activation of this pathway.

Differential expression analysis supports limited regulation of growth rate and membrane transport between soma and germline

To illuminate the potentially distinct roles for Wolbachia in the adult female germline and the somatic hypodermal cords of $O$. ochengi, we compared global transcription in wOo between these tissues. In accordance with the paucity of transcriptional regulators in the $w$ Oo genome, $>96 \%$ of genes displayed a similar level of expression between the two anatomical sites (Fig. 1). However, we identified 26 genes that were differentially expressed at a significance threshold of $P<0.05$ and a false-discovery rate (FDR) of 5\%, encompassing fold-changes (FCs) within the range of 1.9-7.0. It should be noted that because our analysis was restricted to two biological replicates per tissue, it did not constitute a definitive experiment, but rather proof-of-principle that RNA-seq can be used in this context with obligate intracellular organisms despite a vast excess of host transcripts. In addition, the magnitude of these transcriptional differences was relatively modest, although it was comparable to that reported for Wolbachia ankyrin gene expression between male and female gonads in Drosophila spp. as measured by quantitative real-time PCR (qRT-PCR) (Papafotiou et al. 2011).

The pattern of differential expression was predominantly associated with three functional categories: translation machinery, 
DNA replication, and membrane transport (Table 1; Supplemental Table S9). In the germline, elevated expression of genes for elongation factor $\mathrm{Tu}$ (both paralogs), three ribosomal proteins, and the $5 \mathrm{~S}$ rRNA constituted a clear signal of increased protein synthesis. Of these, $r p s U$ encoding ribosomal protein S21 exhibited the greatest FC of any transcript. Although rps $U$ is part of the macromolecular synthesis operon in the Enterobacteriaceae, this is not the case in Wolbachia and many other eubacteria. For instance, expression of an alternative rps $U$ gene cluster in cyanobacteria is regulated by temperature, such that the levels of protein S21 become substoichiometric at $38^{\circ} \mathrm{C}$, despite optimal cell growth (Sato et al. 1997). This suggests that $\mathrm{S} 21$ is not essential for ribosomal function but may have a regulatory role in protein biosynthesis. Two nonstructural components with ancillary roles in translation were also up-regulated in the gonad: polypeptide deformylase (Mazel et al. 1994) and a predicted S-adenosyl-L-methionine-dependent methyltransferase (Pleshe et al. 2005; Savic et al. 2009). Additionally, evidence for a higher rate of DNA replication in this tissue relative to the soma was apparent in the increased expression of uracil-DNA glycosylase, a key enzyme of the base excision system (Holmquist 1998), and a nucleoid DNA-binding protein of the HU family, which exhibits peak expression during the exponential phase of growth in Escherichia coli (Luijsterburg et al. 2006). Moreover, the up-regulated gene annotated as a "cardiolipin synthase" has a conserved domain with closer homology with Nuc, an EDTA-resistant nuclease that digests nucleic acids without sequence specificity (Pohlman et al. 1993). Since Nuc has a signal peptide, it could be involved in the recycling of nucleotides in the host germline to facilitate symbiont cell division. Taken together, the repertoire of genes displaying elevated expression in the gonad is fully consistent with the current understanding of Wolbachia biology in filarial nematodes, as $w \mathrm{Bm}$ divides rapidly during the mitotic proliferation of host oogoniae, and this precedes fertilization of the mature oocytes (Landmann et al. 2010).

Membrane transport, particularly in the periplasmic compartment, was also differentially regulated between the gonad and soma. Whereas two genes involved in rate control of preprotein translocation via the general secretion (Sec) pathway were upregulated in the germline, SecF (Duong and Wickner 1997) and signal peptidase I (Paetzel et al. 2002), the somatic wOo transcriptome was enriched for metal ion transporters and accessory proteins from the respiratory chain (Table 1). These included a cation diffusion facilitator (a family of secondary divalent cation filters associated with resistance to heavy metals), which can transport zinc, iron, cobalt, nickel, and possibly manganese, but not calcium, magnesium, or copper (Nies 2003). Oxidative phosphorylation has a particularly high demand for heavy metal ions, and indeed, a cytochrome $c$ oxidase subunit together with an enzyme that may facilitate cytochrome maturation (thiol-disulfide isomerase) (Sambongi and Ferguson 1994) was up-regulated in the soma. Furthermore, two additional components of the respiratory chain exhibited an FC of more than 1.8-fold in this tissue, although these differences narrowly failed our FDR cut-off (Supplemental Table S6).

Remarkably, two sRNA molecules were among the most differentially expressed transcripts. The up-regulation of a transcriptional regulator in the germline, 6S RNA, was unexpected as it attains maximum concentrations in $E$. coli cells as they enter late stationary phase. Alternatively, as 6S RNA appears to play a critical role in translational adaptation under conditions of nutrient stress (for which a primary signal is nucleotide availability) (Wassarman 2007), increased production in the gonad may reflect the imperative for Wolbachia to synchronize its replication rate with that of the host. In accordance with this hypothesis, 6S RNA is required for optimal intracellular replication of Legionella pneumophila (Faucher et al. 2010). The elevated expression of RNase P in the soma was also surprising, considering its canonical function in the catalysis of precursor tRNA maturation (Kazantsev and Pace 2006). However, RNase $\mathrm{P}$ is a remarkably pleiotropic ribozyme that can regulate the expression of the Sec pathway (Li and Altman 2003) and cleave transient secondary structures in riboswitches (Altman et al. 2005). Thus, the loss of three transcriptional regulator proteins in wOo (Fig. 2) may have resulted in a greater dependency on sRNA mediators in this role.

\section{The profile of abundant proteins includes ligands for mammalian Toll-like receptors}

To determine the degree of concordance between transcript abundance and protein expression and to identify protein products from hypothetical genes, we conducted a proteomic analysis of Wolbachia-enriched material from whole adult female O. ochengi. Unique peptides from a total of $122 \mathrm{wOo}$ proteins were robustly identified $(P<0.01,1 \%$ FDR $)$, representing $18.9 \%$ of

Table 1. Up-regulation of Wolbachia periplasmic protein-encoding genes in the Onchocerca ochengi soma

\begin{tabular}{|c|c|c|c|c|}
\hline Locus tag & Annotation & Fold-change & Putative function $^{a}$ & References \\
\hline wOo08460 & Hypothetical protein & 3.06 & $\begin{array}{l}\text { TrbC/VirB2 pilin subunit of type IV } \\
\text { secretion system }\end{array}$ & Christie et al. (2005) \\
\hline wOo08840 & $\begin{array}{l}\text { Major facilitator superfamily } \\
\text { permease }\end{array}$ & 2.66 & $\begin{array}{l}\text { Secondary active transporter of inorganic } \\
\text { ions or small organic molecules }\end{array}$ & Pao et al. (1998) \\
\hline wOo01770 & Hypothetical protein & 2.46 & $\begin{array}{l}\text { Multiple resistance and pH regulation protein } \\
\text { MrpF; } \mathrm{Na}^{+} / \mathrm{H}^{+} \text {or } \mathrm{K}^{+} / \mathrm{H}^{+} \text {anti-porter }\end{array}$ & $\begin{array}{l}\text { Ito et al. (2000); Putnoky } \\
\text { et al. (1998) }\end{array}$ \\
\hline wOo07860 & Hypothetical protein & 2.22 & $\begin{array}{l}\text { Predicted transmembrane protein with signal } \\
\text { peptide; function unknown }\end{array}$ & - \\
\hline wOo08890 & $\begin{array}{l}\text { Cytochrome } \text { c oxidase, } \\
\text { subunit } 3\end{array}$ & 2.18 & $\begin{array}{l}\text { Stabilizing component of complex IV of the } \\
\text { respiratory chain }\end{array}$ & Haltia et al. (1989) \\
\hline wOo03390 & Thiol-disulfide isomerase & 2.16 & $\begin{array}{l}\text { Thioredoxin family; attachment of haem } \\
\text { to apocytochromes }\end{array}$ & $\begin{array}{l}\text { Sambongi and Ferguson } \\
\text { (1994) }\end{array}$ \\
\hline wOo03990 & $\begin{array}{l}\text { Co Zn Cd efflux system } \\
\text { component }\end{array}$ & 2.13 & $\begin{array}{l}\text { Cation diffusion facilitator family; efflux of heavy } \\
\text { metal ions (ionic radii, } 76-97 \mathrm{pm} \text { ) }\end{array}$ & Nies (2003) \\
\hline
\end{tabular}

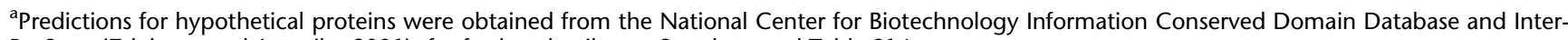
ProScan (Zdobnov and Apweiler 2001); for further details, see Supplemental Table S14. 
predicted proteins encoded by an intact CDS (Supplemental Tables S10, S11). There was a statistically significant relationship between transcript abundance and the detection of corresponding peptides, in that the expression level of genes displaying peptide evidence was significantly higher than for genes lacking detectable peptides $(P<0.001)$ (Supplemental Fig. S5). However, we found no evidence of protein production from pseudogenes, even where they were highly expressed at the transcript level. We used the number of unique peptides detected as an approximate measure of abundance (Supplemental Table S11), and this revealed that GroEL completely dominated the wOo proteome, with almost twice as many unique hits than any other protein. Thus, in common with other obligate intracellular bacteria, Wolbachia GroEL displaces elongation factor Tu as the most highly expressed gene product at the protein level. Importantly, this phenomenon has been described both for other members of the Rickettsiales (Hajem et al. 2009) and more distantly related Proteobacteria (Aksoy 1995; Baumann et al. 1996), irrespective of the nature of the symbiosis. In both Buchnera and the unrelated Blattabacterium, GroEL appears to be under positive selection, and it has been hypothesized that its substrates may have greatly expanded in these obligate intracellular bacteria (Fares et al. 2005). Contrarily, we found no evidence for positive selection in Wolbachia GroEL (Supplemental Table S12).

The dominant metabolism-related subunits in the $w$ Oo proteome were from succinyl-CoA synthetase and ATP synthase, which generate purine nucleoside triphosphates from the tricarboxylic acid cycle and the respiratory chain, respectively. In addition, succinyl-CoA is an essential precursor for the biogenesis of haem. Intense activity at the earlier stages of nucleotide synthesis was reflected by the abundance of glycine-serine hydroxymethyltransferase, the major driver of the one-carbon pool by folate, and of the gluconeogenic enzyme, fructose-bisphosphate aldolase, that produces nucleoside backbones via the nonoxidative pentose phosphate pathway. Overall, and in agreement with metabolic reconstruction in $w \mathrm{Bm}$ (Foster et al. 2005), the $w \mathrm{Oo}$ proteome suggests that amino acids are the principal carbon source, and evidence for the scavenging of sulfur from methionine and cysteine was also apparent (Supplemental Table S13). In contrast with nucleotide and amino acid metabolism, biogenesis of cofactors and vitamins was poorly represented, with few unique peptides detected for enzymes in the folate (FolKP) and haem (HemA, HemC) synthesis pathways.

To perform a comparison of the predominant protein composition in $w \mathrm{Oo}$ and $w \mathrm{Bm}$, we ranked Wolbachia proteins by the number of unique peptides detected in adult female worms of $B$. malayi (Bennuru et al. 2011) and O. ochengi (Supplemental Table S11). Remarkably, this rank ordering showed substantial differences, even on the simple measure of presence in the top 20; although GroEL, DnaK, a single ortholog of Wolbachia surface protein (WSP; wOo07430/wBm0432), and a putative outer membrane protein (wOo08110/wBm0010) predicted to be a porin (Supplemental Table S14) clearly dominated the proteome in both strains. A key conserved feature of $w \mathrm{Oo}$ and $w \mathrm{Bm}$ is the abundance of three proteins (GroEL, WSP, and peptidoglycan-associated lipoprotein [PAL]) that are known to stimulate potent immune responses in the mammalian host. Indeed, GroEL and its eukaryotic homolog (HSP60) from numerous organisms have been demonstrated to induce innate immune signaling and autoimmune reactions (Maguire et al. 2002). For instance, GroEL is the immunodominant antigen in Rickettsia conorii (Renesto et al. 2005), and Porphyromonas gingivalis GroEL is a confirmed ligand for mammalian Toll-like receptor (TLR)-2 and -4 (Argueta et al. 2006). Although the potential for TLR signaling by Wolbachia GroEL has not been investigated in filarial diseases, LF patients exhibiting chronic pathology showed higher IgG1 antibody levels to $w \mathrm{Bm}$ GroEL than did exposed but asymptomatic groups (Suba et al. 2007). However, GroEL may also contribute to the T-cell anergy observed in chronic LF via elevated production of the antiinflammatory cytokines interleukin (IL)-10 and transforming growth factor- $\beta$ (Shiny et al. 2011). A much larger body of data exists pertaining to the immunogenicity of WSP. This molecule is a ligand for TLR-2 and -4 (Brattig et al. 2004) and stimulates production of the pro-inflammatory cytokine IL-8 in neutrophils (Bazzocchi et al. 2003) while inhibiting apoptosis in these cells (Bazzocchi et al. 2007). Moreover, in common with GroEL, antibody levels against WSP are correlated with the disease manifestations of LF (Punkosdy et al. 2003). Finally, PAL has been recently identified as a major inducer of innate pro-inflammatory immune responses in filarial infections. A synthetic diacylated analog of PAL from $w \mathrm{Bm}$ stimulated TLR-2 and -6 , leading to secretion of tumor necrosis factor- $\alpha$ and IL- 8 from mammalian cells in vitro and recruitment of neutrophils into the cornea in the murine keratitis model of River Blindness (Turner et al. 2009).

Diacylation, but not triacylation, of lipoproteins was predicted in $w \mathrm{Bm}$ as its genome encodes genes for prolipoprotein diacylglyceryl transferase and lipoprotein signal peptidase, but not apolipoprotein aminoacyl transferase (Turner et al. 2009). We determined that $w$ Oo has maintained an equivalent repertoire of lipoprotein biosynthesis genes, and thus sought to identify the complete coding potential for lipoproteins using a variety of in silico prediction tools. Intriguingly, despite the reduced genome size of $w$ Oo relative to $w \mathrm{Bm}$, eight putative lipoproteins were identified in the former and only five in the latter, in part due to lack of sequence conservation between paralogs of the type-IV secretion system component, virB6 (Supplemental Table S15). Furthermore, one of the predicted lipoproteins common to both strains, a putative SCO1/SenC family protein, was moderately abundant in the $w$ Oo proteome and could constitute an additional trigger for TLR2/6 signaling. This group of proteins represents thiol-disulfide oxidoreductases and plays an important role in the assembly of the $\mathrm{Cu}_{\mathrm{A}}$ redox center of cytochrome $c$ oxidase in a diverse range of organisms (Banci et al. 2011).

\section{Discussion}

Three principal hypotheses have been proposed to account for the symbiotic relationship between Wolbachia and the Onchocercidae, which are not mutually exclusive. First, Wolbachia may provide metabolites to the worm host that either are unavailable from alternative sources or could become limiting at certain stages of the lifecycle, thus functioning as a nutritional mutualist (Foster et al. 2005). Second, the endobacteria could indirectly interact with the immune system of the definitive (and perhaps the intermediate) host(s) of these filarial parasites, contributing to immune evasion as a defensive mutualist (Hansen et al. 2011). Finally, the obligate dependency of some onchocercids on Wolbachia may not be a mutualism at all, but rather an extreme form of reproductive parasitism that has successfully hijacked normal cellular development in the embryo (Landmann et al. 2011). These hypotheses must contend with two recent and interrelated developments in the field: the demonstration of secondary loss of Wolbachia in several members of the Onchocercidae (McNulty et al. 2010), and the revelation that Wolbachia is currently present in $<40 \%$ of this taxon (Ferri et al. 2011).

\section{Genome Research}

www.genome.org 
The main metabolic candidates that have been proposed to be provisioned by $w \mathrm{Bm}$ are haem, nucleotides, riboflavin, and FAD. The latter two cofactors can be discounted in the case of $w O$ Oo, since the necessary pathway has been pseudogenized. In contrast, a capacity for de novo haem biosynthesis appears to be universally conserved in Wolbachia but is absent (or at least incomplete) both in free-living nematodes such as Caenorhabditis spp. (Rao et al. 2005) and in parasitic species, including B. malayi (Ghedin et al. 2007). Thus, Wolbachia may have become established in the Onchocercidae as a ready source of this essential compound. However, it is important to emphasize that haem autotrophy is almost universal in bacteria (with the exception of some specialized species that reside in mucosal tissue) (Smalley et al. 2011) and appears to be conserved across the Rickettsiales, irrespective of the phenotypic relationship of the bacterium to its host. In addition, ingestion of red blood cells in the filaria Litomosoides sigmodontis has been recorded (Attout et al. 2005), while the intestine of adult O. volvulus (an organ lacking bacteria) contains hemosiderin (George et al. 1985), suggesting that oral uptake of erythrocytes also occurs in this species. Despite these considerations, several lines of evidence indicate a key role for Wolbachia in the maintenance of iron homeostasis (as opposed to simply provisioning). In $D$. melanogaster, $w \mathrm{Mel}$ was shown to confer a fecundity benefit on flies reared on both ecologically relevant, iron-restricted diets and on artificial, iron-overloaded diets (Brownlie et al. 2009). Moreover, in $D$. simulans reared under high-iron conditions, flies infected with $w$ Ri absorbed more iron than did uninfected flies, yet the up-regulation of host ferritin was lower than that observed in uninfected flies (Kremer et al. 2009). In this system, increased expression of Bfr by $w \mathrm{Ri}$ apparently compensated for the host response, although this mechanism cannot apply to wOo, which has lost the Bfr gene. However, up-regulation of a cation diffusion facilitator by $w \mathrm{Oo}$ in host soma could represent an alternative symbiont strategy to control iron metabolism, in which the bacteriophorous vacuole could serve as a buffer zone mediating exchange between host ferroproteins and iron cations.

The importance of nucleotide metabolism was strongly supported both by the retention of key pathways in the wOo genome and the high maintenance of expression of relevant genes. In contrast with haem biosynthesis, the capacity to synthesize nucleotides de novo has been lost by pathogenic rickettsiae (Foster et al. 2005), suggesting a divergence that is relevant to the evolutionary development of parasitism or mutualism. However, the high profile of ATP synthase in the transcriptome and proteome, together with the elevated expression of respiratory chain components by $w$ Oo in the hypodermal cords, suggests that the principal molecule delivered to the worm host is ATP for energy rather than other nucleoside triphosphates for nucleic acid synthesis. Indeed, in accordance with this hypothesis, one of the early signs of morbidity in antibiotic-treated adult worms is a reduction in motility (Gilbert et al. 2005). Moreover, ultrastructural observations of the hypodermal cords in adult $O$. ochengi indicate that Wolbachia density in infected cells greatly exceeds that of mitochondria (Gilbert et al. 2005), perhaps reflecting a functional shift from the organelle to the symbiont for energy generation. In further support of this proposal, tetracycline treatment induced upregulation of mitochondrion-encoded respiratory chain subunits in L. sigmodontis (Strubing et al. 2010), which may represent an attempt by the host to compensate for reduced ATP availability.

Whether Wolbachia has a mutualistic role in the female germline is less clear. It has been suggested that $w \mathrm{Bm}$ supplies nucleotides to the worm host during the period of the lifecycle when the demand for these molecules is greatest; i.e., during embryogenesis (Foster et al. 2005). Our gene expression data for $w \mathrm{Oo}$ within gonad tissue, which revealed the up-regulation of 6S RNA and a secreted nuclease, are more compatible with intense competition between worm and symbiont for nucleotides during oogenesis. However, following fertilization of the oocyte, the pressure on this resource may decrease, since the total number of bacteria per individual host remains relatively constant during embryonic and larval development, up to the third molt (McGarry et al. 2004). This raises the question of how the infection in the oogoniae is maintained when it could have a deleterious effect on the host. In the wasp genus Asobara, various levels of dependency on Wolbachia exist, such that all known wild populations of Asobara tabida require strain $w$ Atab3 to complete normal oogenesis (Kremer et al. 2010). This phenotype appears to be the result of a critical interaction between Wolbachia and an apoptosis checkpoint in the nurse cells of the ovarioles (Pannebakker et al. 2007) because removal of the symbiont triggers widespread host cell death in this tissue. As a minority of antibiotic-cured lines of $A$. tabida can produce very small numbers of viable offspring (Kremer et al. 2010), this obligate dependency is probably evolutionarily recent. Remarkably, the severity of the ovarian phenotype in A. tabida is correlated with the expression of host genes involved in iron homeostasis and oxidative stress (Kremer et al. 2010). Recent studies in B. malayi have demonstrated that apoptosis in the female reproductive tract also follows symbiont depletion by antibiotic treatment (Landmann et al. 2011).

Taken together, these observations suggest that infection of the female germline by Wolbachia can foster dependency relatively rapidly without any obvious fitness benefit to the host, thus representing an "obligate parasitism." This could explain the existence of filarial species that lack symbionts in the hypodermal cords (Ferri et al. 2011), which may be at an early stage of contact with Wolbachia, and of hosts that were once infected with Wolbachia but have become aposymbiotic (such as Onchocerca flexuosa) (McNulty et al. 2010), which could reflect the evolution of countermeasures to regain control of the apoptotic cascade. In addition, if Wolbachia in filarial nematodes is fundamentally a parasitic infection that has secondarily acquired mutualistic traits, the hypothesis that lateral gene transfers of symbiont DNA into the host genome could constitute the capture of useful functions is unlikely to be correct (Fenn and Blaxter 2007). These considerations lead us to conclude that the mutualistic phenotype in filariae arose as a result of Wolbachia colonizing the somatic hypodermal cords. The most probable fitness benefit was an increase in the reproductive lifespan of the worms, since females of $O$. volvulus (and almost certainly $O$. ochengi) remain fecund for $>10 \mathrm{yr}$, whereas O. flexuosa is thought to only live for $\sim 1 \mathrm{yr}$ (Plenge-Bönig et al. 1995). As reactive oxygen species are one of the principal drivers of aging (Buttemer et al. 2010), we propose that the ability of Wolbachia to perform aerobic respiration and to metabolize iron while maintaining an elevated oxidative stress response are key mechanisms that promote infection of somatic tissues in filariae.

The longevity of $O$. volvulus and $O$. ochengi is also dependent on an ability to withstand the local immune response of the definitive host while enclosed within a fibrous nodule. In both of these species, Wolbachia is responsible for the recruitment of an ineffective neutrophilia around the adult worms (Brattig et al. 2001; Nfon et al. 2006), which persists for the duration of the worms' lifespan. However, when Wolbachia is depleted from $O$. ochengi by oxytetracycline treatment, neutrophils are replaced by the classic helminthotoxic effector cell, eosinophils, which infiltrate 
into the nodule and degranulate on the filarial cuticle, eventually resulting in worm death (Hansen et al. 2011). As this sequence of events is specifically triggered by disruption of the symbiosis rather than anthelminthic chemotherapy per se, $w$ Oo could be considered a defensive mutualist. This phenotype is now well recognized for Wolbachia in arthropods, and a precedent involving manipulation of the immune system of a third party exists for an insect pest of maize (Barr et al. 2010). Moreover, in L. sigmodontis, successful migration of the infective larvae is also associated with immunomodulation of mammalian effector cells by Wolbachia (Specht et al. 2011). The abundance of TLR ligands with known or suspected chemo-attractant activity for neutrophils in the wOo proteome (WSP and PAL, and perhaps GroEL and SCO1) provides strong support for the hypothesis that Wolbachia not only stimulates the mammalian immune response but also can manipulate it in such a manner that the filarial host can survive for more than a decade.

In conclusion, our global analysis of gene expression in $w \mathrm{Oo}$ provides an unprecedented insight into the complexity of an organism that can mediate different host interactions in separate tissue compartments, despite extensive genome reduction. Thus, we urge caution, following the recent explosion of knowledge regarding Wolbachia phenotypes in arthropods, in any attempt to circumscribe the filarial-Wolbachia relationship in terms of a single process. In addition, we emphasize that our study was restricted to wOo within adult worms, and the stage-specificity of symbiotic interactions has been recognized in other systems, such as the enterobacterial symbionts of entomopathogenic nematodes (Koppenhöfer and Gaugler 2009).

\section{Methods}

\section{Parasite material}

Nodules containing adult $O$. ochengi parasites were obtained from the skins of cattle slaughtered at Ngaoundéré abattoir in the Adamawa Region of Cameroon (Wahl et al. 1994). Adult male and female worms were separated from excised nodules; the gonads were removed from the latter (selecting only nongravid individuals) and stored in PBS or RNAlater (Sigma) at $-80^{\circ} \mathrm{C}$, whereas the males were preserved whole. The material was transported to the United Kingdom on dry ice and stored at $-80^{\circ} \mathrm{C}$.

\section{Nucleic acid extractions}

O. ochengi genomic DNA was extracted using DNAzol (Invitrogen) from approximately 150 male worms in PBS or $\sim 20 \mathrm{mg}$ female gonads in RNAlater. For transcriptomic analyses, total RNA was purified from the worm material stored in RNAlater using TRI Reagent (Sigma). For further details, see the Supplemental Methods.

\section{Genome sequence}

The $w$ Oo genome assembly was generated from the O. ochengi DNA extracts using an initial data set obtained on a Genome Sequencer FLX System (454 Life Sciences, Roche Diagnostics) and assembled in Newbler (454 Life Sciences), which was corrected for homopolymer length errors with additional reads from a Genome Analyzer IIx (Illumina) platform (final coverage, $70 \times$ ). The sequence was analyzed using Prodigal to call protein-coding genes, tRNAscanSE (Lowe and Eddy 1997) to locate tRNA genes, MUMmer (Kurtz et al. 2004) to detect repeats, ISSaga (Varani et al. 2011) to identify IS elements, BLAST (Altschul et al. 1990) and InterProScan (Zdobnov and Apweiler 2001) to assign putative functions to protein-coding genes, and ORTHOMCL (Li et al. 2003) to define orthologs shared with other Wolbachia strains. Metabolic pathways were examined using the SEED (Overbeek et al. 2005) and Kyoto Encyclopaedia of Genes and Genomes (Kanehisa and Goto 2000) databases. Pseudogenes were classified as regions with homology with previously annotated bacterial genes but that showed evidence of disruption by premature stop codons or frameshift mutations. In addition to the automated correction of the 454 assembly using Illumina genomic reads, putative pseudogenes were checked for data inconsistencies manually using both the Illumina data set and SOLiD transcript reads (see below). Finally, mass spectrometric data from protein samples (see below) were searched against six-frame translations of highly transcribed pseudogene fragments and expressed intergenic regions, as identified by Cufflinks (Trapnell et al. 2010). For further details, see the Supplemental Methods.

\section{Synthesis and purification of cDNA}

Contaminating genomic DNA in the RNA samples was digested using a TURBO DNA-free Kit (Ambion) according to the manufacturer's instructions. For first-strand cDNA synthesis, $\sim 2.5 \mu \mathrm{g}$ RNA was reverse-transcribed using a Moloney murine leukemia virus reverse-transcriptase (RT) kit (Bioline), as specified by the manufacturer. Second-strand synthesis was performed with E. coli DNA ligase, DNA polymerase I, RNase $\mathrm{H}$, and T4 DNA polymerase in $1 \times$ Second-Strand Reaction Buffer (all supplied by Invitrogen). The double-stranded (ds) cDNA was purified by phenol-chloroform extraction, dissolved in nuclease-free water, and stored at $-20^{\circ} \mathrm{C}$. For further details, see the Supplemental Methods.

\section{Transcriptome sequencing and analysis}

The ds cDNA samples (two biological replicates from male or female worms) were used to generate standard SOLiD fragment libraries and run as a multiplex on three SOLiD (version 4; Applied Biosystems) slide quadrants in total. The resulting reads where mapped to the finished genome using Bowtie (Langmead et al. 2009). Transcript expression was analyzed using Cufflinks (Trapnell et al. 2010) to find novel expressed regions in the genome, whereas differential expression was calculated using reads counts generated from bam2rpkm freeware (obtained from SourceForge) and analyzed using edgeR (Bioconductor), with a negative binomial distribution model. To identify sRNA genes, noncoding regions exhibiting high levels of transcription were analyzed using Rfam (Griffiths-Jones et al. 2003). For further details, see the Supplemental Methods.

\section{Sample preparation for proteomic analysis}

To provide Wolbachia-enriched samples for proteomic analysis, $600 \mathrm{mg}$ of fresh adult female $O$. ochengi was processed using the FOCUS Mitochondria kit (G-Biosciences) according to the manufacturer's instructions for soft tissues. Proteins were separated under reducing conditions on a $15 \%$ polyacrylamide gel and visualized using a Colloidal Blue Staining Kit (Invitrogen). Thirty gel slices from a single lane (30 $\mu$ g total protein) were digested with trypsin, and five pooled fractions were analyzed by mass spectrometry (MS). For further details, see the Supplemental Methods.

\section{Liquid chromatography-MS and data analysis}

Tryptic peptides were analyzed by high-resolution liquid chromatography (LC) MS/MS on an LTQ-Orbitrap Velos (Thermo Fisher Scientific). Peptide identifications were established using the Mascot (Matrix Science) search engine against a custom database. Search parameters included a precursor mass tolerance of 10 
ppm and fragment mass tolerance of $0.5 \mathrm{Da}$, while one missed tryptic cleavage was permitted. Carbamidomethylation was set as a fixed modification, and oxidation (M) was included as a variable modification. A significance threshold of $P<0.01$ was applied to the Mascot ion score, and the FDRs were set at $<1 \%$. For further details, see the Supplemental Methods.

\section{Data access}

The genome data have been submitted to the NCBI GenBank (http:// www.ncbi.nlm.nih.gov/genbank/) (accession PRJEA81837) and EMBL-Bank (http://www.ebi.ac.uk/embl/) (accession HE660029). The RNA-seq data are available from the Sequence Read Archive (accession SRP014524), and the mass spectrometric data can be downloaded from the Tranche repository at ProteomeCommons.org (hash +7EETqKbefFAa9amw1vZmw2VD36SYyrAjtRf1h7fXkaXQeWTVp0/ HX3ihjTt2lhoQrpqjVXxRon5f5TK74c6BU3TDXMAAAAAAAAElw==).

\section{Acknowledgments}

We thank David Ekale and Henrietta Ngangyung (IRAD, Cameroon) for the collection of parasite material, Dong Xia for bioinformatic support, and Neil Hall for co-management of the Royal College of Veterinary Surgeons (RCVS) award. This work was funded by the European Commission (contracts INCO-CT-2006-032321 and HEALTH-F3-2010-242131) and the Golden Jubilee Fund of the RCVS Charitable Trust. R.C. was supported by a European Research Council Starting Grant (FP7-2007-2013, contract 260729 "EndoSexDet").

Author's contributions: B.L.M., S.D.A., G.S.B., M.A.H., P.K., L.R., and S.M.K. performed the experiments; A.C.D., B.L.M., S.D.A., R.C., G.K., and M.L.B. analyzed the data; B.L.M., R.C., A.C.D., and S.D.A. wrote the paper; G.S.B. and V.N.T. provided unique materials; and B.L.M., A.C.D., S.D.A., A.J.T., V.N.T., J.M.W., and A.D.R. conceived and managed the project.

\section{References}

Aksoy S. 1995. Molecular analysis of the endosymbionts of tsetse flies: 16S rDNA locus and over-expression of a chaperonin. Insect Mol Biol 4: 23-29.

Altman S, Wesolowski D, Guerrier-Takada C, Li Y. 2005. RNase P cleaves transient structures in some riboswitches. Proc Natl Acad Sci 102: 1128411289.

Altschul SF, Gish W, Miller W, Myers EW, Lipman DJ. 1990. Basic local alignment search tool. J Mol Biol 215: 403-410.

Argueta JG, Shiota S, Yamaguchi N, Masuhiro Y, Hanazawa S. 2006 Induction of Porphyromonas gingivalis GroEL signaling via binding to Toll-like receptors 2 and 4. Oral Microbiol Immunol 21: 245-251.

Attout T, Babayan S, Hoerauf A, Taylor DW, Kozek WJ, Martin C, Bain O. 2005. Blood-feeding in the young adult filarial worms Litomosoides sigmodontis. Parasitology 130: 421-428.

Banci L, Bertini I, Cavallaro G, Ciofi-Baffoni S. 2011. Seeking the determinants of the elusive functions of Sco proteins. FEBS J 278: 2244-2262.

Bandi C, McCall JW, Genchi C, Corona S, Venco L, Sacchi L. 1999. Effects of tetracycline on the filarial worms Brugia pahangi and Dirofilaria immitis and their bacterial endosymbionts Wolbachia. Int J Parasitol 29: 357364.

Barr KL, Hearne LB, Briesacher S, Clark TL, Davis GE. 2010. Microbial symbionts in insects influence down-regulation of defense genes in maize. PLOS ONE 5: e11339. doi: 10.1371/journal.pone.0011339.

Baumann P, Baumann L, Clark MA. 1996. Levels of Buchnera aphidicola chaperonin GroEL during growth of the aphid Schizaphis graminum. Curr Microbiol 32: 279-285

Bazzocchi C, Genchi C, Paltrinieri S, Lecchi C, Mortarino M, Bandi C. 2003. Immunological role of the endosymbionts of Dirofilaria immitis: The Wolbachia surface protein activates canine neutrophils with production of IL-8. Vet Parasitol 117: 73-83.

Bazzocchi C, Comazzi S, Santoni R, Bandi C, Genchi C, Mortarino M. 2007. Wolbachia surface protein (WSP) inhibits apoptosis in human neutrophils. Parasite Immunol 29: 73-79.
Bennuru S, Meng Z, Ribeiro JM, Semnani RT, Ghedin E, Chan K, Lucas DA, Veenstra TD, Nutman TB. 2011. Stage-specific proteomic expression patterns of the human filarial parasite Brugia malayi and its endosymbiont Wolbachia. Proc Natl Acad Sci 108: 9649-9654.

Brattig NW, Büttner DW, Hoerauf A. 2001. Neutrophil accumulation around Onchocerca worms and chemotaxis of neutrophils are dependent on Wolbachia endobacteria. Microbes Infect 3: 439-446.

Brattig NW, Bazzocchi C, Kirschning CJ, Reiling N, Büttner DW, Ceciliani F, Geisinger F, Hochrein H, Ernst M, Wagner H, et al. 2004. The major surface protein of Wolbachia endosymbionts in filarial nematodes elicits immune responses through TLR2 and TLR4. J Immunol 173: 437-445.

Brownlie JC, Cass BN, Riegler M, Witsenburg JJ, Iturbe-Ormaetxe I, McGraw EA, O'Neill SL. 2009. Evidence for metabolic provisioning by a common invertebrate endosymbiont, Wolbachia pipientis, during periods of nutritional stress. PLoS Pathog 5: e1000368. doi: 10.1371/ journal.ppat.1000368.

Buttemer WA, Abele D, Costantini D. 2010. From bivalves to birds: Oxidative stress and longevity. Funct Ecol 24: 971-983.

Cerveau N, Leclercq S, Leroy E, Bouchon D, Cordaux R. 2011. Short- and long-term evolutionary dynamics of bacterial insertion sequences: Insights from Wolbachia endosymbionts. Genome Biol Evol 3: 1175-1186.

Christie PJ, Atmakuri K, Krishnamoorthy V, Jakubowski S, Cascales E. 2005. Biogenesis, architecture, and function of bacterial type IV secretion systems. Annu Rev Microbiol 59: 451-485.

Dedeine F, Vavre F, Fleury F, Loppin B, Hochberg ME, Bouletreau M. 2001. Removing symbiotic Wolbachia bacteria specifically inhibits oogenesis in a parasitic wasp. Proc Natl Acad Sci 98: 6247-6252.

Duong F, Wickner W. 1997. The SecDFyajC domain of preprotein translocase controls preprotein movement by regulating SecA membrane cycling. EMBO J 16: 4871-4879.

Fares MA, Moya A, Barrio E. 2005. Adaptive evolution in GroEL from distantly related endosymbiotic bacteria of insects. J Evol Biol 18: 651-660.

Faucher SP, Friedlander G, Livny J, Margalit H, Shuman HA. 2010. Legionella pneumophila 6S RNA optimizes intracellular multiplication. Proc Natl Acad Sci 107: 7533-7538.

Fenn K, Blaxter M. 2007. Coexist, cooperate and thrive: Wolbachia as longterm symbionts of filarial nematodes. In Wolbachia: A bug's life in another bug (ed. A Hoerauf, RU Rao), pp. 66-76. Karger, Basel, Switzerland.

Ferri E, Bain O, Barbuto M, Martin C, Lo N, Uni S, Landmann F, Baccei SG, Guerrero R, de Souza LS, et al. 2011. New insights into the evolution of Wolbachia infections in filarial nematodes inferred from a large range of screened species. PLoS ONE 6: e20843. doi: 10.1371/ journal.pone.0020843.

Foster J, Ganatra M, Kamal I, Ware J, Makarova K, Ivanova N, Bhattacharyya A, Kapatral V, Kumar S, Posfai J, et al. 2005. The Wolbachia genome of Brugia malayi: Endosymbiont evolution within a human pathogenic nematode. PLoS Biol 3: e121. doi: 10.1371/journal.pbio.0030121.

George GH, Palmieri JR, Connor DH. 1985. The onchocercal nodule: Interrelationship of adult worms and blood vessels. Am J Trop Med Hyg 34: 1144-1148.

Ghedin E, Wang S, Spiro D, Caler E, Zhao Q, Crabtree J, Allen JE, Delcher AL, Guiliano DB, Miranda-Saavedra D, et al. 2007. Draft genome of the filarial nematode parasite Brugia malayi. Science 317: 1756-1760.

Gilbert J, Nfon CK, Makepeace BL, Njongmeta LM, Hastings IM, Pfarr KM, Renz A, Tanya VN, Trees AJ. 2005. Antibiotic chemotherapy of onchocerciasis: In a bovine model, killing of adult parasites requires a sustained depletion of endosymbiotic bacteria (Wolbachia species). J Infect Dis 192: 1483-1493.

Griffiths-Jones S, Bateman A, Marshall M, Khanna A, Eddy SR. 2003. Rfam: An RNA family database. Nucleic Acids Res 31: 439-441.

Haegeman A, Vanholme B, Jacob J, Vandekerckhove TT, Claeys M, Borgonie G, Gheysen G. 2009. An endosymbiotic bacterium in a plant-parasitic nematode: Member of a new Wolbachia supergroup. Int J Parasitol 39: 1045-1054.

Hajem N, Weintraub A, Nimtz M, Romling U, Pahlson C. 2009. A study of the antigenicity of Rickettsia helvetica proteins using two-dimensional gel electrophoresis. APMIS 117: 253-262.

Haltia T, Finel M, Harms N, Nakari T, Raitio M, Wikstrom M, Saraste M. 1989. Deletion of the gene for subunit III leads to defective assembly of bacterial cytochrome oxidase. EMBO J 8: 3571-3579.

Hansen RD, Trees AJ, Bah GS, Hetzel U, Martin C, Bain O, Tanya VN, Makepeace BL. 2011. A worm's best friend: Recruitment of neutrophils by Wolbachia confounds eosinophil degranulation against the filarial nematode Onchocerca ochengi. Proc Biol Sci 278: 2293-2302.

Hansson M, Hederstedt L. 1994. Bacillus subtilis HemY is a peripheral membrane protein essential for protoheme IX synthesis which can oxidize coproporphyrinogen III and protoporphyrinogen IX. J Bacteriol 176: $5962-5970$.

Henrichfreise B, Schiefer A, Schneider T, Nzukou E, Poellinger C, Hoffmann TJ, Johnston KL, Moelleken K, Wiedemann I, Pfarr K, et al. 2009. 
Functional conservation of the lipid II biosynthesis pathway in the cell wall-less bacteria Chlamydia and Wolbachia: Why is lipid II needed? Mol Microbiol 73: 913-923.

Hilgenboecker K, Hammerstein P, Schlattmann P, Telschow A, Werren JH. 2008. How many species are infected with Wolbachia? A statistical analysis of current data. FEMS Microbiol Lett 281: 215-220.

Hoerauf A. 2008. Filariasis: New drugs and new opportunities for lymphatic filariasis and onchocerciasis. Curr Opin Infect Dis 21: 673-681.

Hoerauf A, Nissen-Pähle K, Schmetz C, Henkle-Dührsen K, Blaxter ML, Büttner DW, Gallin MY, Al-Qaoud KM, Lucius R, Fleischer B. 1999. Tetracycline therapy targets intracellular bacteria in the filarial nematode Litomosoides sigmodontis and results in filarial infertility. J Clin Invest 103: 11-18.

Holman AG, Davis PJ, Foster JM, Carlow CK, Kumar S. 2009. Computational prediction of essential genes in an unculturable endosymbiotic bacterium, Wolbachia of Brugia malayi. BMC Microbiol 9: 243. doi: 10.1186/1471-2180-9-243.

Holmquist GP. 1998. Endogenous lesions, S-phase-independent spontaneous mutations, and evolutionary strategies for base excision repair. Mutat Res 400: 59-68.

Hosokawa T, Koga R, Kikuchi Y, Meng XY, Fukatsu T. 2010. Wolbachia as a bacteriocyte-associated nutritional mutualist. Proc Natl Acad Sci 107: 769-774.

Ito M, Guffanti AA, Wang W, Krulwich TA. 2000. Effects of nonpolar mutations in each of the seven Bacillus subtilis mrp genes suggest complex interactions among the gene products in support of $\mathrm{Na}^{+}$and alkali but not cholate resistance. J Bacteriol 182: 5663-5670.

Kanehisa M, Goto S. 2000. KEGG: Kyoto Encyclopedia of Genes and Genomes. Nucleic Acids Res 28: 27-30.

Kazantsev AV, Pace NR. 2006. Bacterial RNase P: A new view of an ancient enzyme. Nat Rev Microbiol 4: 729-740.

Klasson L, Walker T, Sebaihia M, Sanders MJ, Quail MA, Lord A, Sanders S, Earl J, O'Neill SL, Thomson N, et al. 2008. Genome evolution of Wolbachia strain $w$ Pip from the Culex pipiens group. Mol Biol Evol 25: 1877-1887.

Klasson L, Westberg J, Sapountzis P, Naslund K, Lutnaes Y, Darby AC, Veneti Z, Chen L, Braig HR, Garrett R, et al. 2009. The mosaic genome structure of the Wolbachia wRi strain infecting Drosophila simulans. Proc Natl Acad Sci 106: $5725-5730$.

Koppenhöfer HS, Gaugler R. 2009. Entomopathogenic nematode and bacteria mutualism. In Defensive mutualism in microbial symbiosis (ed. JF White, MS Torres), pp. 99-116. CRC Press, Boca Raton, FL.

Kremer N, Voronin D, Charif D, Mavingui P, Mollereau B, Vavre F. 2009. Wolbachia interferes with ferritin expression and iron metabolism in insects. PLoS Pathog 5: e1000630. doi: 10.1371/journal.ppat.1000630.

Kremer N, Dedeine F, Charif D, Finet C, Allemand R, Vavre F. 2010. Do variable compensatory mechanisms explain the polymorphism of the dependence phenotype in the Asobara tabida-Wolbachia association? Evolution 64: 2969-2979.

Kurtz S, Phillippy A, Delcher AL, Smoot M, Shumway M, Antonescu C, Salzberg SL. 2004. Versatile and open software for comparing large genomes. Genome Biol 5: R12. doi: 10.1186/gb-2004-5-2-r12.

Landmann F, Foster JM, Slatko B, Sullivan W. 2010. Asymmetric Wolbachia segregation during early Brugia malayi embryogenesis determines its distribution in adult host tissues. PLoS Negl Trop Dis 4: e758. doi: 10.1371/journal.pntd.0000758.

Landmann F, Voronin D, Sullivan W, Taylor MJ. 2011. Anti-filarial activity of antibiotic therapy is due to extensive apoptosis after Wolbachia depletion from filarial nematodes. PLoS Pathog 7: e1002351. doi: 10.1371/journal.ppat.1002351.

Langmead B, Trapnell C, Pop M, Salzberg SL. 2009. Ultrafast and memoryefficient alignment of short DNA sequences to the human genome. Genome Biol 10: R25. doi: 10.1186/gb-2009-10-3-r25.

Langworthy NG, Renz A, Mackenstedt U, Henkle-Dührsen K, de Bronsvoort MB, Tanya VN, Donnelly MJ, Trees AJ. 2000. Macrofilaricidal activity of tetracycline against the filarial nematode Onchocerca ochengi: Elimination of Wolbachia precedes worm death and suggests a dependent relationship. Proc Biol Sci 267: 1063-1069.

Leclercq S, Giraud I, Cordaux R. 2011. Remarkable abundance and evolution of mobile group II introns in Wolbachia bacterial endosymbionts. Mol Biol Evol 28: 685-697.

Li Y, Altman S. 2003. A specific endoribonuclease, RNase P, affects gene expression of polycistronic operon mRNAs. Proc Natl Acad Sci 100: 13213-13218.

Li L, Stoeckert CJ Jr, Roos DS. 2003. OrthoMCL: Identification of ortholog groups for eukaryotic genomes. Genome Res 13: 2178-2189.

Lo N, Paraskevopoulos C, Bourtzis K, O'Neill SL, Werren JH, Bordenstein SR, Bandi C. 2007. Taxonomic status of the intracellular bacterium Wolbachia pipientis. Int I Syst Evol Microbiol 57: 654-657.

Lowe TM, Eddy SR. 1997. tRNAscan-SE: A program for improved detection of transfer RNA genes in genomic sequence. Nucleic Acids Res 25: 955964.
Luijsterburg MS, Noom MC, Wuite GJ, Dame RT. 2006. The architectural role of nucleoid-associated proteins in the organization of bacterial chromatin: A molecular perspective. J Struct Biol 156: 262-272.

Maguire M, Coates AR, Henderson B. 2002. Chaperonin 60 unfolds its secrets of cellular communication. Cell Stress Chaperones 7: 317-329.

Mazel D, Pochet S, Marliere P. 1994. Genetic characterization of polypeptide deformylase, a distinctive enzyme of eubacterial translation. EMBO J 13: 914-923.

McGarry HF, Egerton GL, Taylor MJ. 2004. Population dynamics of Wolbachia bacterial endosymbionts in Brugia malayi. Mol Biochem Parasitol 135: 57-67.

McNulty SN, Foster JM, Mitreva M, Dunning Hotopp JC, Martin J, Fischer K, Wu B, Davis PJ, Kumar S, Brattig NW, et al. 2010. Endosymbiont DNA in endobacteria-free filarial nematodes indicates ancient horizontal genetic transfer. PLOS ONE 5: e11029. doi: 10.1371/ journal.pone.0011029.

Miller WJ, Ehrman L, Schneider D. 2010. Infectious speciation revisited: Impact of symbiont-depletion on female fitness and mating behavior of Drosophila paulistorum. PLoS Pathog 6: e1001214. doi: 10.1371/ journal.ppat.1001214.

Morales-Hojas R, Cheke RA, Post RJ. 2006. Molecular systematics of five Onchocerca species (Nematoda: Filarioidea) including the human parasite, O. volvulus, suggest sympatric speciation. J Helminthol 80: 281-290.

Nfon CK, Makepeace BL, Njongmeta LM, Tanya VN, Bain O, Trees AJ. 2006. Eosinophils contribute to killing of adult Onchocerca ochengi within onchocercomata following elimination of Wolbachia. Microbes Infect 8: 2698-2705.

Nies DH. 2003. Efflux-mediated heavy metal resistance in prokaryotes. FEMS Microbiol Rev 27: 313-339.

Overbeek R, Begley T, Butler RM, Choudhuri JV, Chuang HY, Cohoon M, de Crecy-Lagard V, Diaz N, Disz T, Edwards R, et al. 2005. The subsystems approach to genome annotation and its use in the project to annotate 1000 genomes. Nucleic Acids Res 33: 5691-5702.

Paetzel M, Karla A, Strynadka NC, Dalbey RE. 2002. Signal peptidases. Chem Rev 102: 4549-4580.

Pannebakker BA, Loppin B, Elemans CP, Humblot L, Vavre F. 2007. Parasitic inhibition of cell death facilitates symbiosis. Proc Natl Acad Sci 104: 213215.

Pao SS, Paulsen IT, Saier MH Jr. 1998. Major facilitator superfamily. Microbiol Mol Biol Rev 62: 1-34.

Papafotiou G, Oehler S, Savakis C, Bourtzis K. 2011. Regulation of Wolbachia ankyrin domain encoding genes in Drosophila gonads. Res Microbiol 162: 764-772.

Pichon S, Bouchon D, Cordaux R, Chen L, Garrett RA, Greve P. 2009. Conservation of the Type IV secretion system throughout Wolbachia evolution. Biochem Biophys Res Commun 385: 557-562.

Plenge-Bönig A, Krömer M, Büttner DW. 1995. Light and electron microscopy studies on Onchocerca jakutensis and O. flexuosa of red deer show different host-parasite interactions. Parasitol Res 81: 66-73.

Pleshe E, Truesdell J, Batey RT. 2005. Structure of a class II TrmH tRNAmodifying enzyme from Aquifex aeolicus. Acta Crystallogr Sect F Struct Biol Cryst Commun 61: 722-728.

Pohlman RF, Liu F, Wang L, More MI, Winans SC. 1993. Genetic and biochemical analysis of an endonuclease encoded by the IncN plasmid pKM101. Nucleic Acids Res 21: 4867-4872.

Punkosdy GA, Addiss DG, Lammie PJ. 2003. Characterization of antibody responses to Wolbachia surface protein in humans with lymphatic filariasis. Infect Immun 71: 5104-5114.

Putnoky P, Kereszt A, Nakamura T, Endre G, Grosskopf E, Kiss P, Kondorosi A. 1998. The pha gene cluster of Rhizobium meliloti involved in $\mathrm{pH}$ adaptation and symbiosis encodes a novel type of $\mathrm{K}^{+}$efflux system. Mol Microbiol 28: 1091-1101.

Rao AU, Carta LK, Lesuisse E, Hamza I. 2005. Lack of heme synthesis in a free-living eukaryote. Proc Natl Acad Sci 102: 4270-4275.

Renesto P, Azza S, Dolla A, Fourquet P, Vestris G, Gorvel JP, Raoult D. 2005. Proteome analysis of Rickettsia conorii by two-dimensional gel electrophoresis coupled with mass spectrometry. FEMS Microbiol Lett 245: 231-238.

Rocha EPC. 2004. The replication-related organization of bacterial genomes. Microbiology-SGM 150: 1609-1627.

Sambongi Y, Ferguson SJ. 1994. Specific thiol compounds complement deficiency in c-type cytochrome biogenesis in Escherichia coli carrying a mutation in a membrane-bound disulphide isomerase-like protein. FEBS Lett 353: 235-238.

Sato N, Tachikawa T, Wada A, Tanaka A. 1997. Temperature-dependent regulation of the ribosomal small-subunit protein S21 in the cyanobacterium Anabaena variabilis M3. J Bacteriol 179: 7063-7071.

Savic M, Lovric J, Tomic TI, Vasiljevic B, Conn GL. 2009. Determination of the target nucleosides for members of two families of $16 \mathrm{~S}$ rRNA methyltransferases that confer resistance to partially overlapping groups of aminoglycoside antibiotics. Nucleic Acids Res 37: 5420-5431. 
Shiny C, Krushna NS, Babu S, Elango S, Manokaran G, Narayanan RB. 2011. Recombinant Wolbachia heat shock protein 60 (HSP60) mediated immune responses in patients with lymphatic filariasis. Microbes Infect 13: $1221-1231$.

Smalley JW, Byrne DP, Birss AJ, Wojtowicz H, Sroka A, Potempa J, Olczak T. 2011. HmuY haemophore and gingipain proteases constitute a unique syntrophic system of haem acquisition by Porphyromonas gingivalis. PLoS ONE 6: e17182. doi: 10.1371/journal.pone.0017182.

Specht S, Frank JK, Alferink J, Dubben B, Layland LE, Denece G, Bain O, Forster I, Kirschning CJ, Martin C, et al. 2011. CCL17 controls mast cells for the defense against filarial larval entry. J Immunol 186: 4845-4852.

Strubing U, Lucius R, Hoerauf A, Pfarr KM. 2010. Mitochondrial genes for hemedependent respiratory chain complexes are up-regulated after depletion of Wolbachia from filarial nematodes. Int J Parasitol 40: 1193-1202.

Suba N, Shiny C, Taylor MJ, Narayanan RB. 2007. Brugia malayi Wolbachia hsp60 IgG antibody and isotype reactivity in different clinical groups infected or exposed to human bancroftian lymphatic filariasis. Exp Parasitol 116: 291-295.

Timmermans MJTN, Ellers J. 2009. Wolbachia endosymbiont is essential for egg hatching in a parthenogenetic arthropod. Evol Ecol 23: 931-942.

Trapnell C, Williams BA, Pertea G, Mortazavi A, Kwan G, van Baren MJ, Salzberg SL, Wold BJ, Pachter L. 2010. Transcript assembly and quantification by RNA-Seq reveals unannotated transcripts and isoform switching during cell differentiation. Nat Biotechnol 28: 511-515.

Trees AJ. 1992. Onchocerca ochengi: Mimic, model or modulator of O. volvulus? Parasitol Today 8: 337-339.
Turner JD, Langley RS, Johnston KL, Gentil K, Ford L, Wu B, Graham M, Sharpley F, Slatko B, Pearlman E, et al. 2009. Wolbachia lipoprotein stimulates innate and adaptive immunity through Toll-like receptors 2 and 6 to induce disease manifestations of filariasis. J Biol Chem 284: 22364-22378.

Varani AM, Siguier P, Gourbeyre E, Charneau V, Chandler M. 2011. ISsaga is an ensemble of web-based methods for high throughput identification and semi-automatic annotation of insertion sequences in prokaryotic genomes. Genome Biol 12: R30. doi: $10.1186 / \mathrm{gb}-2011-12-3-\mathrm{r} 30$.

Wahl G, Achukwi MD, Mbah D, Dawa O, Renz A. 1994. Bovine onchocercosis in north Cameroon. Vet Parasitol 52: 297-311.

Wassarman KM. 2007. 6S RNA: A small RNA regulator of transcription. Curr Opin Microbiol 10: 164-168.

Wu M, Sun LV, Vamathevan J, Riegler M, Deboy R, Brownlie JC, McGraw EA, Martin W, Esser C, Ahmadinejad N, et al. 2004. Phylogenomics of the reproductive parasite Wolbachia pipientis $w \mathrm{Mel}$ : A streamlined genome overrun by mobile genetic elements. PLoS Biol 2: E69. doi: 10.1371/ journal.pbio.0020069.

Zdobnov EM, Apweiler R. 2001. InterProScan: An integration platform for the signature-recognition methods in InterPro. Bioinformatics 17: 847848 .

Received February 1, 2012; accepted in revised form July 27, 2012. 


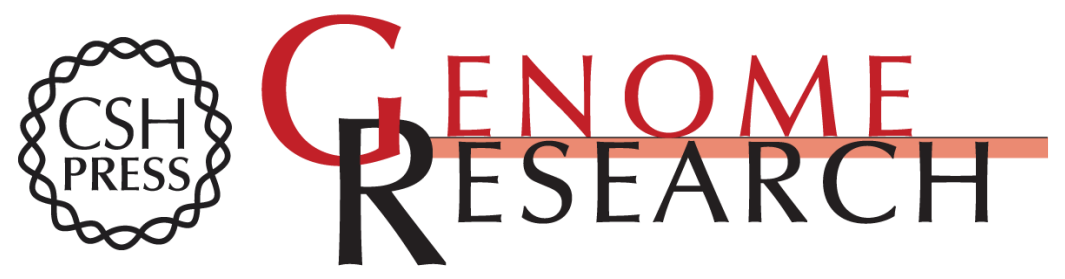

\title{
Analysis of gene expression from the Wolbachia genome of a filarial nematode supports both metabolic and defensive roles within the symbiosis
}

\author{
Alistair C. Darby, Stuart D. Armstrong, Germanus S. Bah, et al.
}

Genome Res. 2012 22: 2467-2477 originally published online August 23, 2012

Access the most recent version at doi:10.1101/gr.138420.112

\section{Supplemental http://genome.cshlp.org/content/suppl/2012/09/20/gr.138420.112.DC1 \\ Material}

References This article cites 97 articles, 21 of which can be accessed free at:

http://genome.cshlp.org/content/22/12/2467.full.html\#ref-list-1

Open Access Freely available online through the Genome Research Open Access option.

Creative This article is distributed exclusively by Cold Spring Harbor Laboratory Press for the Commons

License first six months after the full-issue publication date (see

http://genome.cshlp.org/site/misc/terms.xhtml). After six months, it is available under a Creative Commons License (Attribution-NonCommercial 3.0 Unported License), as described at http://creativecommons.org/licenses/by-nc/3.0/.

Email Alerting Receive free email alerts when new articles cite this article - sign up in the box at the Service top right corner of the article or click here.

\section{Affordable, Accurate Sequencing.}

To subscribe to Genome Research go to:

https://genome.cshlp.org/subscriptions 